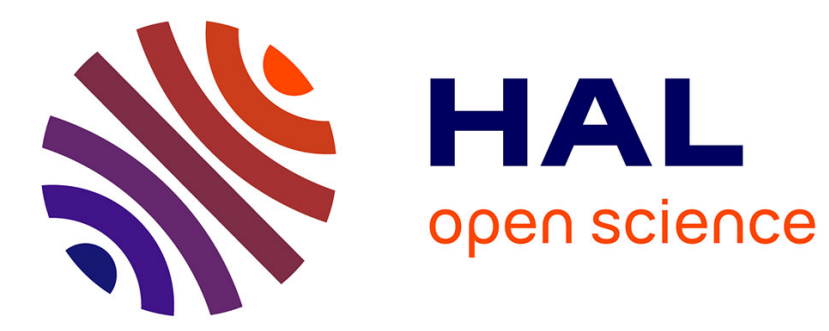

\title{
Anticipatory postural adjustments during cutting manoeuvres in football and their consequences for knee injury risk
}

\author{
Guillaume Mornieux, D. Gehring, P Furst, Albert Gollhofer
}

\section{To cite this version:}

Guillaume Mornieux, D. Gehring, P Furst, Albert Gollhofer. Anticipatory postural adjustments during cutting manoeuvres in football and their consequences for knee injury risk. Journal of Sports Sciences, 2014, 32 (13), pp.1255-1262. 10.1080/02640414.2013.876508 . hal-01710046

\section{HAL Id: hal-01710046 \\ https://hal.univ-lorraine.fr/hal-01710046}

Submitted on 25 Apr 2021

HAL is a multi-disciplinary open access archive for the deposit and dissemination of scientific research documents, whether they are published or not. The documents may come from teaching and research institutions in France or abroad, or from public or private research centers.
L'archive ouverte pluridisciplinaire HAL, est destinée au dépôt et à la diffusion de documents scientifiques de niveau recherche, publiés ou non, émanant des établissements d'enseignement et de recherche français ou étrangers, des laboratoires publics ou privés. 
Title:

Anticipatory postural adjustments during cutting manoeuvres in football and their consequences for knee injury risk.

Authors:

Guillaume Mornieux, Dominic Gerhring, Patrick Fürst, Albert Gollhofer

Running Title:

Anticipative strategies during cutting manoeuvres.

\section{Original Research}

Key words: change of direction, trunk, knee abduction moment, head rotation, step width.

Word count: Introduction through conclusion, 4197 words 


\section{Abstract}

Anticipatory postural adjustments (APA), i.e. preparatory positioning of the head, the trunk and the foot, are essential to initiate cutting manoeuvres during football games. The aim of the present study was to determine how APA strategies during cutting manoeuvres are influenced by a reduction of the time available to prepare the movement.

Thirteen football players performed different cutting tasks, with directions of cutting either known prior the task or indicated by a light signal occurring $850 \mathrm{~ms}, 600 \mathrm{~ms}$ or $500 \mathrm{~ms}$ before ground contact.

With less time available to prepare the cutting manoeuvre, the head was less orientated towards the cutting direction $(\mathrm{p}=0.033)$ and the trunk was even more rotated in the opposite direction $(\mathrm{p}=0.002)$, while the foot placement was not significantly influenced. Moreover, the induced higher lateral trunk flexion correlated with the increased knee abduction moment $(\mathrm{r}=0.41 ; \mathrm{p}=0.009)$.

Increasing lateral trunk flexion is the main strategy used to successfully perform a cutting manoeuvre when less time is available to prepare the movement. However, higher lateral trunk flexion was associated with an increased knee abduction moment and therefore an increased knee injury risk. Reducing lateral trunk flexion during cutting manoeuvres should be part of training programs seeking the optimization of APAs. 


\section{Introduction}

Changing the direction or avoiding obstacles is an integral part of many team sports as for instance football. It is evident that preparatory strategies, so-called anticipatory postural adjustments (APA), are necessary for a successful movement execution (Jindrich \& Qiao, 2009; Patla, Adkin, \& Ballard, 1999; Xu, Carlton, \& Rosengren, 2004). Basically, changing direction requires a reorientation of the body together with the impulse vector to move the centre of mass $(\mathrm{CoM})$ in the direction of the intended movement. This could be achieved by three main strategies involving the whole body. Firstly, the foot placement via the step width regulation plays an important role (Patla et al., 1999; Vallis \& McFadyen, 2003; Wheeler \& Sayers, 2010). Indeed, the placement of the foot determines the position of the centre of pressure and defines in which direction the CoM can be accelerated (Patla et al., 1999). Secondly, head orientation is used to adjust the visual field and to initiate the reorientation of the whole body (Hicheur, Vieilledent, \& Berthoz, 2005; Sreenivasa, Frissen, Souman, \& Ernst, 2008; Vallis \& McFadyen, 2005). Finally, the control of trunk motion is crucial (Sreenivasa et al., 2008; Vallis \& McFadyen, 2005). The trunk yaw (rotation about the long axis of the body) orientates the body in the new direction. Moreover, the trunk roll (lateral flexion) is used to move lower limbs and upper body in opposite directions, which allows moving the CoM towards the new direction during the stance phase (Patla et al., 1999), especially when the change of direction occurs late. It is worth noting that APAs must already be planned and initiated in the step before changing the direction (Patla et al., 1999; Vallis \& McFadyen, 2005).

Changes of direction can be performed differently, e.g. side-stepping, cutting or crossover manoeuvres during various sport disciplines. The way APAs initiate and organize the movement (manoeuvrability) influences the performance (Jindrich \& 
Qiao, 2009). For instance it has been reported that higher skilled rugby players demonstrate faster changes of direction than less skilled players (Gabbett \& Benton, 2009).

But manoeuvrability is also associated with injury risk (Jindrich \& Qiao, 2009). Indeed, lateral movements with changes of direction may lead to misalignments in the lower extremities with the consequence that the knee may be at a relatively high risk of injuries, such as anterior cruciate ligament ruptures (Alentorn-Geli et al., 2009; Olsen, Myklebust, Engebretsen, \& Bahr, 2004). As football is the most commonly practiced sport in the world, the injury concern in this activity is even higher than in other sports (Alentorn-Geli et al., 2009), which underlines the need for researchers to keep improving the body of knowledge dealing with knee injury mechanisms and risk factors associated with football practice. Moreover, knee injuries are often experienced in an unpredictable setting, as for instance perturbed landing or insufficient time to prepare the movement (Olsen et al., 2004). Experimental results revealed that knee joint loading, especially knee valgus moment, was greater during unpredictable conditions and consequently may have increased the risk of knee injuries during these cutting manoeuvres (Besier, Lloyd, Ackland, \& Cochrane, 2001; Houck, Duncan, \& Haven, 2006).

Therefore, the influence of unpredictable conditions on APAs during cutting manoeuvres and their consequences for knee injury risk are of interest. Increasing the body of knowledge dealing with APAs would help to further understand how performance and safety could be improved during such tasks typically encountered during football games. In addition to the unpredictability of the upcoming change of direction, the time available to prepare the movement plays an important role as recently proposed by Brown, Palmieri-Smith and McLean (2009). Although anticipatory postural adjustment strategies have been fairly well described during 
changes of direction, their limitations have not been investigated so far during critical situations, i.e. during a cutting manoeuvre with little time available to prepare.

The aim of the present study was to determine which APAs are the most relevant during cutting manoeuvres in football and which fail when time available to prepare the movement is limited. We hypothesized that football players would increase their lateral trunk flexion when the time available to prepare the cutting manoeuvre was reduced. Finally, we aimed to evaluate the consequences for knee injury risk resulting from these APA failures.

\section{Materials and methods}

\section{Participants}

Using data from the literature evaluating unanticipated movements (Brown et al., 2009), the sample size was estimated to achieve $80 \%$ statistical power with an alpha level of 0.05 . Accordingly, thirteen male amateur football players (age: $24 \pm 3$ years old; height: $1.79 \pm 0.03 \mathrm{~m}$; mass: $73.8 \pm 7.4 \mathrm{~kg}$; football experience: $>10$ years in the $5^{\text {th }}-7^{\text {th }}$ German league) participated in the study. Prior to testing, all participants were informed about possible risks and gave written informed consent. Participants did not have a previous history of serious knee injury or any current knee pain. All procedures were approved by the local ethics committee.

\section{Protocol}

Football players were asked to perform three different tasks in a randomized order, including a cutting manoeuvre to $45^{\circ}$, a crossover to $-20^{\circ}$ and a straight run with an 
approach running speed of $5 \pm 0.2 \mathrm{~m} \cdot \mathrm{s}^{-1}$. The tasks were performed on a force plate and were followed by a maximal sprint over a $4 \mathrm{~m}$ distance.

The direction of the movement was indicated by a light signal occurring at different times before the left foot contacted the force plate. The first condition was anticipated (Ant), meaning that participants already knew which light would turn on before starting to run. For this condition the light stimulus appeared $850 \mathrm{~ms}$ before ground contact. The three other cutting conditions were performed without this knowledge, while the light stimulus was presented $850 \mathrm{~ms}$, 600ms and $500 \mathrm{~ms}$ before ground contact. The rationale for these delays was determined during pilot measurements. $850 \mathrm{~ms}$ was considered long enough to prepare the movement in a similar manner to the Ant condition. In this condition the light stimulus appeared approximately 3 steps (during right foot contact) before the change of direction. $600 \mathrm{~ms}$ was felt by the participants to be a typical time constraint comparable to game situations and the signal occurred during the initial contact of the left foot two steps prior to changing the direction. From this value, we decreased the time available until players started to fail in the task execution, but not in more than $20 \%$ of the trials. In this condition (i.e. 500ms condition), the light stimulus occurred during the push off phase of the left foot contact two steps prior to the change of direction.

The order of the four time conditions was randomly assigned over the 13 participants. Participants performed the movements on an artificial football turf (Ecofill@, Mondo S.p.A., Alba, Italy) while wearing the same neutral football shoe (Predator, Adidas, Herzogenaurach, Germany). All participants were used to such movements due to their football practice and were also familiar with the light stimulus procedure, as they had already participated in studies using this testing setup.

During the present study, participants had to perform about 80 running and cutting movements to ensure eight successful $45^{\circ}$ cutting manoeuvres for each time condition. 
Participants had at least 30 seconds recovery after each trial but could rest as long as they wanted to avoid the onset of fatigue.

The $45^{\circ}$ cutting manoeuvre was the only movement to be further analyzed due to its relevance when investigating performance and injury aspects of changing direction tasks (see introduction). A trial was defined as successful if the approach speed was reached, the left foot hit the force plate and the sprint was conducted in the direction of the light stimulus already one step after the force plate.

\section{Material}

The approach running speed was measured over the last $3 \mathrm{~m}$ before the force plate (Timer S3, Alge-Timing, Palling, Germany) and the sprint velocity over the first $3 \mathrm{~m}$ after the force plate were recorded by means of light switches (M18 series, Panasonic Electric Works Europe AG, Holzkirchen, Germany).

The visual light stimulus was triggered automatically via a light switch (M18 series, Panasonic Electric Works Europe AG, Holzkirchen, Germany), triggered during the approach run. The three lights were placed at eye level in the directions of the three tasks, $7 \mathrm{~m}$ away from the forceplate.

Three-dimensional head, trunk and leg kinematics were recorded using reflective skin markers $(\varnothing 14 \mathrm{~mm})$ placed with self-adhesive tape on anatomical landmarks of the participants' head, trunk, pelvis and both right and left legs. Specifically, markers were placed around the head (four markers), on the suprasternal notch and the transition between the body of sternum and the xiphoid process as well as on the T6 vertebra, on the anterior and posterior superior iliac spines, on the great trochanter, medial and lateral epicondyle of the knee, tibia (two markers) and the medial and lateral malleolus of the left leg, and on the posterior, medial and lateral aspects of the heel cup as well as the toe of both feet. This marker placement was based on previously published 
articles for the head (Sreenivasa et al., 2008) and the lower limb (Fleischmann et al., 2010). The marker positions for the trunk segment were developed based on the conclusions reported by Leardini, Biagi, Belvedere and Benedetti (2009). Markers were captured with a 12-camera motion analysis system (Vicon V-MX, VICON Motion Systems Ltd., Oxford, UK) at a sampling frequency of $200 \mathrm{~Hz}$. A static trial with the subject standing in a pre-defined neutral position was used to define the kinematic model and to calculate segment lengths and joint centres (Grood \& Suntay, 1983; Wu et al., 2002). Joint kinematics in three rotational degrees of freedom were determined using an yxz Euler rotation sequence of the respective segment coordinate system. Marker trajectory and ground reaction force (BP600900, AMTI, Watertown, USA) signals were both filtered with a low pass Butterworth filter $\left(4^{\text {th }}\right.$ order, $20 \mathrm{~Hz}$ cut-off frequency) prior to calculating external joint moments with a standard inverse dynamics approach.

\section{Data analysis}

Kinematic parameters were first investigated at the end of the right foot contact, i.e. one step prior to the change of direction, as the body posture at this moment would represent the APAs and would also help to understand the organization of the transition

phase between APAs and the moment of the change of direction. The right heel strike and toe off were determined based on the peak vertical acceleration signal of the heel marker and toe marker, respectively. Head rotation, trunk rotation and lateral trunk flexion with respect to the global coordinate system as well as step width were calculated (for positive orientation see Figure 1).

Then the kinematic parameters were analyzed at the time of the peak knee abduction moment during the left foot contact during the cutting manoeuvre, as this is a relevant parameter associated with knee injury (Hewett et al., 2005). Again, head rotation, trunk 
rotation and lateral trunk flexion as well as step width were determined. In addition, the foot progression angle was defined as the rotation of the calcaneus in relation to the global coordinate system. Moreover, hip and knee joint moments in the frontal plane were analyzed.

$* * * *$ Figure 1 near here $* * * *$

\section{Statistics}

The selected biomechanical parameters were averaged across eight trials for each subject in each cutting condition and served as the basis for the statistical analysis (SPSS 20.0, IBM SPSS Statistics, IBM Corporation, Armonk, NY, USA). After having confirmed that the data followed a normal distribution (Kolmogorov-Smirnov test), main effects of cutting condition (Ant vs. $850 \mathrm{~ms}$ vs. $600 \mathrm{~ms}$ vs. $500 \mathrm{~ms}$ ) on the dependent biomechanical variables were tested using a one-way analysis of variance (General Linear Model) with repeated measures. Pearson's correlation coefficient was used to determine the relation between lateral trunk flexion and peak knee abduction moment during the cutting manoeuvre (Jamison, Pan, \& Chaudhari, 2012). The level of significance was set at 0.05 . If a statistically significant main effect was observed, LSD multiple comparison procedures determined where the differences occurred. All results are presented as group means \pm SD.

\section{Results}


One step before changing the direction, there was a significant influence of the cutting condition on head rotation $(\mathrm{p}=0.033)$, trunk rotation $(\mathrm{p}=0.002)$ and lateral trunk flexion $(\mathrm{p}<0.001)$, whereas step width was not reduced $(\mathrm{p}=0.081)$ (see Table 1$)$.

In the cutting condition with $600 \mathrm{~ms}$ the head was significantly less rotated to the right compared to both Ant and $850 \mathrm{~ms}(\mathrm{p}=0.033$ and $\mathrm{p}=0.028$, respectively), while higher trunk rotation to the left was found for both $600 \mathrm{~ms}$ and $500 \mathrm{~ms}$ compared to Ant and $850 \mathrm{~ms}(\mathrm{p}<0.026)$ and higher lateral trunk flexion values were reported for both $600 \mathrm{~ms}$ and $500 \mathrm{~ms}$ than Ant and $850 \mathrm{~ms}(\mathrm{p}<0.001)$. None of these parameters were significantly different between Ant and $850 \mathrm{~ms}$, as well as between $600 \mathrm{~ms}$ and $500 \mathrm{~ms}$.

At the time of the peak knee abduction moment, there was a significant influence of the cutting condition on head rotation $(\mathrm{p}=0.015)$, trunk rotation $(\mathrm{p}=0.028)$ and lateral trunk flexion $(\mathrm{p}<0.001)$, whereas step width and foot progression angle were not altered (Table 2).

During the cutting condition with $600 \mathrm{~ms}$ the head was significantly less orientated towards the right compared to both Ant and $850 \mathrm{~ms}(\mathrm{p}=0.032$ and $\mathrm{p}=0.018$, respectively). The $500 \mathrm{~ms}$ and $600 \mathrm{~ms}$ cutting conditions yielded larger trunk rotation to the left than $850 \mathrm{~ms}$ ( $\mathrm{p}=0.036$ and $\mathrm{p}=0.043$, respectively). Compared to both Ant and $850 \mathrm{~ms}$, lateral trunk flexion values were significantly higher for $600 \mathrm{~ms}(\mathrm{p}<0.002)$ and 500ms ( $\mathrm{p}<0.001)$. Additionally, the lateral trunk flexion was higher for 500ms than 600ms $(\mathrm{p}=0.015)$. None of these parameters were significantly different between Ant and $850 \mathrm{~ms}$.

Mean values of the parameters dealing with the loading of the lower limb at the time of the peak knee abduction moment are reported in Table 3. Along with the reduction of the time to prepare the cutting manoeuvre, there was a significant increase of the 
posterior $(\mathrm{p}<0.001)$ and vertical ground reaction forces $(\mathrm{p}<0.001)$. The cutting condition significantly influenced both hip $(\mathrm{p}<0.001)$ and knee abduction moments $(\mathrm{p}<0.001)$. Moreover, the contact time was influenced by the cutting condition $(\mathrm{p}<0.001)$.

Again, none of these parameters were significantly different between Ant and 850ms. Compared to Ant and $850 \mathrm{~ms}$, posterior ground reaction force was significantly higher for $600 \mathrm{~ms}$ ( $\mathrm{p}=0.005$ and $\mathrm{p}=0.024$, respectively) and $500 \mathrm{~ms}(\mathrm{p}<0.001$ for both), while $500 \mathrm{~ms}$ even yielded a higher posterior ground reaction force than $600 \mathrm{~ms}(\mathrm{p}=0.04)$. The vertical ground reaction force during the cutting condition with $600 \mathrm{~ms}$ was significantly higher than Ant and $850 \mathrm{~ms}(\mathrm{p}=0.003$ and $\mathrm{p}=0.015$, respectively). In the same manner, performing the cutting manoeuvre with 500ms resulted in higher vertical ground reaction forces than both Ant $(\mathrm{p}=0.001)$ and $850 \mathrm{~ms}(\mathrm{p}=0.006)$. The $500 \mathrm{~ms}$ cutting condition yielded increased hip abduction moment compared to Ant $(\mathrm{p}=0.002)$ and $850 \mathrm{~ms}(\mathrm{p}=0.007)$, as well as increased knee abduction moment compared to Ant $(\mathrm{p}=0.001)$ and $850 \mathrm{~ms}(\mathrm{p}=0.003)$. The same observation could be made for $600 \mathrm{~ms}$, which, compared to Ant and 850ms, generated higher hip and knee abduction moments ( $p<0.009$ and $p<0.011$, respectively). Compared to Ant and $850 \mathrm{~ms}$, contact time values were significantly higher for $600 \mathrm{~ms}(\mathrm{p}=0.007$ and $\mathrm{p}=0.002$, respectively) and $500 \mathrm{~ms}$ ( $<<0.001$ for both). Additionally, the contact time was longer for $500 \mathrm{~ms}$ than $600 \mathrm{~ms}$ $(\mathrm{p}=0.008)$.

To further understand the influence of lateral trunk flexion on knee abduction moment, variations from the Ant condition baseline in the three unpredictable cutting conditions for these two parameters were plotted together (Figure 2). Lateral trunk flexion significantly correlated with peak knee abduction moment $(\mathrm{r}=0.41 ; \mathrm{p}=0.009)$. 
Sprint velocity remained comparable over the four cutting conditions, ranging from $5.0 \pm 0.4 \mathrm{~m} . \mathrm{s}^{-1}$ for Ant to $4.9 \pm 0.3 \mathrm{~m} . \mathrm{s}^{-1}$ with a delay of $500 \mathrm{~ms}$.

\section{Discussion}

The primary finding of the present study was that APAs are modulated according to the time available to prepare a cutting manoeuvre. Participants relied on a higher lateral trunk flexion to perform cutting manoeuvres under limited time available. While this was an effective strategy to maintain the sprint performance, higher lateral trunk flexion was associated with increased knee abduction moment. Finally, as soon as the time available was sufficient $(850 \mathrm{~ms})$, not knowing in advance in which direction one would have to cut did not influence APAs, knee joint loading or sprint performance.

Of the three main APA strategies proposed in the literature, lateral trunk flexion was the most influenced by the cutting condition. Head and trunk rotations were also influenced by the time available to prepare the cutting manoeuvre, whereas the step width regulation was not significantly altered.

With less time available, lateral trunk flexion increased by $10.3^{\circ}$ (500ms vs. Ant) already one step prior to the cutting manoeuvre and by $8.4^{\circ}$ at the time of the change of direction $150 \mathrm{~ms}$ later. This finding is in agreement with data from previous studies (Houck et al., 2006; Patla et al., 1999). Lateral trunk flexion was even more increased in the present study compared to the $+3.7^{\circ}$ found by Houck et al. (2006) when participants performed a $50^{\circ}$ cutting task under unpredictable conditions but with a lower approach velocity of $1.9 \mathrm{~m} . \mathrm{s}^{-1}$. The higher lateral trunk flexion can be seen as a strategy to move the $\mathrm{CoM}$ in the new direction. A neuromuscular explanation for this 
increased lateral trunk flexion strategy could be the relative higher strength of the trunk and hip muscles compared to other rather weak muscles (e.g. ankle invertors/evertors) during the stance phase. Therefore, participants could rely more on their trunk than on any foot placement strategy.

Head and trunk rotations were influenced to some degree by the time restriction to prepare the cutting manoeuvre. With less time available, the head was less orientated towards the cutting direction and the trunk was even more rotated in the opposite direction at the time of changing the direction as well as one step before. The rotation of the trunk in the opposite direction has already been reported in the literature during cutting manoeuvers (Dempsey et al., 2007; Dempsey, Lloyd, Elliott, Steele, \& Munro, 2009). The influence of the cutting condition on head and trunk rotations was limited, as for instance no significant difference was observed between the 500ms and Ant conditions at the time of the peak knee abduction moment or given that standard deviation values for the head $\left(7^{\circ}\right.$ to $\left.13^{\circ}\right)$ and the trunk $\left(7^{\circ}\right.$ to $\left.11^{\circ}\right)$ were large. The relatively small influence of the time available on these APAs further shows the weak importance of head and trunk rotation strategies during cutting manoeuvres.

The step width strategy depends on the foot placement. One step prior to changing the direction, a medial shift of the foot placement with respect to the CoM would allow the centre of mass to accelerate towards the new direction. However, this strategy tended to be less used under critical time conditions $(<600 \mathrm{~ms})$. Moreover, the subsequent foot contact when changing the direction was not modulated, i.e. the foot was not placed more laterally to increase the acceleration of the CoM in the cutting direction. This result is in agreement with Patla et al. (1999) and partially consistent with Wheeler and Sayers (2010) and Houck et al. (2006). Indeed, as soon as the change of direction was unpredictable, the first authors reported that the step width strategy was significantly less used one step prior to changing the direction and the latter 
authors found a reduction of the step width at the time of the cutting manoeuvre. Moreover, less use of the step width strategy one step before the change of direction was associated with reduced lateral movement speed (Wheeler \& Sayers, 2010). Therefore, the step width strategy does not seem to be the one to increase or to rely on during challenging cutting manoeuvres.

Accordingly, altering lateral trunk flexion is probably the most relevant postural strategy to successfully perform a cutting manoeuvre under unpredictable conditions and to maintain the subsequent sprint performance at the same level.

Despite obvious main effects of the cutting condition on APAs, it is worth noting that further statistical analysis revealed no significant difference between Ant and 850ms. Accordingly, not knowing in advance which cutting manoeuvre will have to be executed does not influence APA strategies as long as the time available to prepare the movement is long enough. Under the present conditions, i.e. $5 \mathrm{~m} \cdot \mathrm{s}^{-1}$ approach velocity and $45^{\circ}$ cut angle, a time of $850 \mathrm{~ms}$ ( 3 steps prior to the change of direction) was enough to use postural strategies comparable to those observed under predictable conditions.

Whereas lateral trunk flexion was increased during successful cutting manoeuvres under limited time to prepare the movement, the overall leg loading as well as the joint loading increased. Indeed, posterior and vertical ground reaction forces at the time of the peak knee abduction moment (roughly 20-25ms after foot strike) were significantly higher for both the $600 \mathrm{~ms}$ and the $500 \mathrm{~ms}$ cutting conditions. This higher loading of the leg could increase the difficulty of the task, requiring significantly longer contact time and explaining also why $20 \%$ of the cutting manoeuvres with 500ms time available were not successful. 
Moreover, hip and knee joint moments increased in the frontal plane as soon as the time available decreased to $600 \mathrm{~ms}$. This observation is in agreement with previous results showing increased joint loading under unpredictable conditions (Besier et al., 2001; Brown et al., 2009), although Dempsey et al. (2009) reported no significant influence of unpredictability on knee joint moments under conditions comparable to the present study (approach velocity, cutting angle and light stimulus timing). The large peak knee abduction moment values (up to $1.24 \mathrm{Nm}_{\mathrm{kg}}{ }^{-1}$ ) are consistent with recently published data (Vanrenterghem, Venables, Pataky, \& Robinson, 2012) and underline the high loading of the knee and the possible risk for knee injury. The substantial new information provided by the present study is that not only cutting angle or approach velocity or even the unpredictability about the cutting condition influence knee joint loading but also the time available to prepare the cutting manoeuvre.

The increased lateral trunk flexion due to the reduction of the time available explained approximately $17 \%$ of the variance in peak knee abduction moment and should therefore be considered as an important parameter when investigating knee injury mechanisms (Figure 2). This association confirms previous observations dealing with the mechanical coupling between trunk and knee joint in the frontal plane (Dempsey et al., 2009; Hewett \& Myer, 2011; Houck et al., 2006; Jamison et al., 2012).

Thus, it can be concluded that altered APA strategies under unpredictable conditions are one factor leading to an increased knee joint injury risk during cutting manoeuvres, along with, for instance, less suitable neuromuscular activity of the knee joint muscles (Besier, Lloyd, \& Ackland, 2003).

Accordingly, the aim of future studies could be to provide solutions for this excessive use of lateral trunk flexion. Reducing the use of this strategy would then probably need to be compensated by other anticipatory postural strategies to maintain 
the subsequent sprint performance at the same level. For instance it is known that head and trunk rotation strategies tend to be reduced with maturation (Vallis \& McFadyen, 2005). Therefore, training these strategies again to improve the re-orientation of the whole body based on a head and trunk rotation might be a relevant solution. Another solution could be a modified foot placement. Dempsey et al. (2009) have already reported a reduction of knee joint loading associated with a specific whole body cutting technique, characterized by a medial shift of the foot together with a more neutral lateral trunk flexion at the time when changing the direction. However, even if a more externally rotated foot placement, i.e. the foot progression angle, might be a strategy to reduce knee joint frontal plane loading (Fleischmann, Gehring, Mornieux, \& Gollhofer, 2010; Sigward \& Powers, 2007), this parameter was not influenced by the cutting conditions in the present study. Therefore, modulation of the foot rotation does not seem to be an appropriate strategy to prepare a cutting manoeuvre under limited time available.

It has to be emphasized that any cutting technique modification through a training intervention would probably be more effective if attention is brought to the step prior to the change of direction, whichever strategy, i.e. head rotation, trunk rotation or step width regulation, is trained.

The relevance of the present results can be transferred to daily football training. Firstly, training should put emphasis on decision making situations, where players have to identify ball trajectories, teammate or opponent displacements that are not pre-defined and make the appropriate decision accordingly (relevant timing and direction of the pass or displacement). Secondly, training should focus on situations where players experience one against one situations (either by attacking or defending) and where changes of direction are required. During these situations, players would focus on their trunk rotation and the lateral trunk flexion to operate such cutting manoeuvres. The 
upper body should not only be kept straight but orientated towards the new direction of the cutting manoeuvre. Moreover, players should pay attention to the alignment of the leg and the upper body already one step prior to the change of direction.

To conclude, this study provides a detailed biomechanical and functional analysis of anticipatory postural adjustment strategies during cutting manoeuvres in football. From the variables analysed in the present study, increasing lateral trunk flexion is the most effective strategy to successfully perform a cutting manoeuvre when less time is available to prepare the movement. But this is also associated with increased knee injury risk. Considering knee injury as a serious issue in football, training programs need to improve anticipatory postural adjustments to reduce injury risk and possibly enhance performance. 


\section{Literature}

Alentorn-Geli, E., Myer, G. D., Silvers, H. J., Samitier, G., Romero, D., LázaroHaro, C., \& Cugat, R. (2009). Prevention of non-contact anterior cruciate ligament injuries in soccer players. Part 1: Mechanisms of injury and underlying risk factors. Knee surgery, sports traumatology, arthroscopy: official journal of the ESSKA, 17(7), 705-729. Retrieved from http://www.ncbi.nlm.nih.gov/pubmed/19452139

Besier, T. F., Lloyd, D. G., Ackland, T. R., \& Cochrane, J. L. (2001). Anticipatory effects on knee joint loading during running and cutting maneuvers. Medicine and science in sports and exercise, 33(7), 1176-1181. Retrieved from http://www.ncbi.nlm.nih.gov/pubmed/11445765

Besier, T. F., Lloyd, D. G., \& Ackland, T. R. (2003). Muscle activation strategies at the knee during running and cutting maneuvers. Medicine and science in sports and exercise, 35(1), 119-127. Retrieved from http://www.ncbi.nlm.nih.gov/pubmed/12544645

Brown, T. N., Palmieri-Smith, R. M., \& McLean, S. G. (2009). Sex and limb differences in hip and knee kinematics and kinetics during anticipated and unanticipated jump landings: implications for anterior cruciate ligament injury. British journal of sports medicine, 43(13), 1049-56. doi:10.1136/bjsm.2008.055954

Dempsey, A. R., Lloyd, D. G., Elliott, B. C., Steele, J. R., \& Munro, B. J. (2009). Changing sidestep cutting technique reduces knee valgus loading. The American journal of sports medicine, 37(11), 2194-200. doi:10.1177/0363546509334373

Dempsey, A. R., Lloyd, D. G., Elliott, B. C., Steele, J. R., Munro, B. J., \& Russo, K. A. (2007). The effect of technique change on knee loads during sidestep cutting. Medicine and science in sports and exercise, 39(10), 1765-1773. Retrieved from http://www.ncbi.nlm.nih.gov/pubmed/17909404

Fleischmann, J., Gehring, D., Mornieux, G., \& Gollhofer, A. (2010). Load-dependent movement regulation of lateral stretch shortening cycle jumps. European journal of applied physiology, 110(1), 177-187. Retrieved from http://www.ncbi.nlm.nih.gov/pubmed/20443023

Gabbett, T., \& Benton, D. (2009). Reactive agility of rugby league players. Journal of science and medicine in sport / Sports Medicine Australia, 12(1), 212-4. doi:10.1016/j.jsams.2007.08.011

Grood, E. S., \& Suntay, W. J. (1983). A joint coordinate system for the clinical description of three-dimensional motions: application to the knee. Journal of biomechanical engineering, 105(2), 136-44. Retrieved from http://www.ncbi.nlm.nih.gov/pubmed/6865355 
Hewett, T. E., \& Myer, G. D. (2011). The mechanistic connection between the trunk, hip, knee, and anterior cruciate ligament injury. Exercise and sport sciences reviews, 39(4), 161-6. doi:10.1097/JES.0b013e3182297439

Hewett, T. E., Myer, G. D., Ford, K. R., Heidt, R. S., Colosimo, A. J., McLean, S. G., Van den Bogert, A. J., et al. (2005). Biomechanical measures of neuromuscular control and valgus loading of the knee predict anterior cruciate ligament injury risk in female athletes: a prospective study. The American journal of sports medicine, 33(4), 492-501. Retrieved from http://www.ncbi.nlm.nih.gov/pubmed/15722287

Hicheur, H., Vieilledent, S., \& Berthoz, A. (2005). Head motion in humans alternating between straight and curved walking path: combination of stabilizing and anticipatory orienting mechanisms. Neuroscience letters, 383(1-2), 87-92. doi:10.1016/j.neulet.2005.03.046

Houck, J. R., Duncan, A., \& Haven, K. E. (2006). Comparison of frontal plane trunk kinematics and hip and knee moments during anticipated and unanticipated walking and side step cutting tasks. Gait \& posture, 24(3), 314-322. Retrieved from http://www.ncbi.nlm.nih.gov/pubmed/16293416

Jamison, S. T., Pan, X., \& Chaudhari, A. M. W. (2012). Knee moments during runto-cut maneuvers are associated with lateral trunk positioning. Journal of biomechanics, 45(11), 1881-5. doi:10.1016/j.jbiomech.2012.05.031

Jindrich, D. L., \& Qiao, M. (2009). Maneuvers during legged locomotion. Chaos (Woodbury, N.Y.), 19(2), 26105. Retrieved from http://www.ncbi.nlm.nih.gov/pubmed/19566265

Leardini, A., Biagi, F., Belvedere, C., \& Benedetti, M. G. (2009). Quantitative comparison of current models for trunk motion in human movement analysis. Clinical biomechanics (Bristol, Avon), 24(7), 542-50. doi:10.1016/j.clinbiomech.2009.05.005

Olsen, O.-E., Myklebust, G., Engebretsen, L., \& Bahr, R. (2004). Injury mechanisms for anterior cruciate ligament injuries in team handball: a systematic video analysis. The American journal of sports medicine, 32(4), 1002-1012. Retrieved from http://www.ncbi.nlm.nih.gov/pubmed/15150050

Patla, A. E., Adkin, A., \& Ballard, T. (1999). Online steering: coordination and control of body center of mass, head and body reorientation. Experimental brain research, 129(4), 629-634. Retrieved from http://www.ncbi.nlm.nih.gov/pubmed/10638436

Sigward, S. M., \& Powers, C. M. (2007). Loading characteristics of females exhibiting excessive valgus moments during cutting. Clinical biomechanics (Bristol, Avon), 22(7), 827-833. Retrieved from http://www.ncbi.nlm.nih.gov/pubmed/17531364

Sreenivasa, M. N., Frissen, I., Souman, J. L., \& Ernst, M. O. (2008). Walking along curved paths of different angles: the relationship between head and trunk 
turning. Experimental brain research. Experimentelle Hirnforschung.

Expérimentation cérébrale, 191(3), 313-20. doi:10.1007/s00221-008-1525-3

Vallis, L. A., \& McFadyen, B. J. (2003). Locomotor adjustments for circumvention of an obstacle in the travel path. Experimental brain research. Experimentelle Hirnforschung. Expérimentation cérébrale, 152(3), 409-14.

doi:10.1007/s00221-003-1558-6

Vallis, L. A., \& McFadyen, B. J. (2005). Children use different anticipatory control strategies than adults to circumvent an obstacle in the travel path. Experimental brain research. Experimentelle Hirnforschung. Expérimentation cérébrale, 167(1), 119-27. doi:10.1007/s00221-005-0054-6

Vanrenterghem, J., Venables, E., Pataky, T., \& Robinson, M. a. (2012). The effect of running speed on knee mechanical loading in females during side cutting. Journal of biomechanics, 45(14), 2444-9. doi:10.1016/j.jbiomech.2012.06.029

Wheeler, K. W., \& Sayers, M. G. L. (2010). Modification of agility running technique in reaction to a defender in rugby union. Journal of Sports Science and Medicine, 9, 445-451.

Wu, G., Siegler, S., Allard, P., Kirtley, C., Leardini, A., Rosenbaum, D., Whittle, M., et al. (2002). ISB recommendation on definitions of joint coordinate system of various joints for the reporting of human joint motion-part I: ankle, hip and spine. Journal of biomechanical engineering, 35, 543-548. Retrieved from http://www.ncbi.nlm.nih.gov/pubmed/22357196

Xu, D., Carlton, L. G., \& Rosengren, K. S. (2004). Anticipatory postural adjustments for altering direction during walking. Journal of motor behavior, 36(3), 316-26. doi:10.3200/JMBR.36.3.316-326 


\section{Tables}

Table 1

\begin{tabular}{l|cccc}
\hline & Ant & $850 \mathrm{~ms}$ & $600 \mathrm{~ms}$ & $500 \mathrm{~ms}$ \\
\hline Head rotation $\left(^{\circ}\right)$ & $11.1 \pm 9.1$ & $10.9 \pm 9.9$ & $6.5 \pm 10.5 * \mathrm{a}$ & $6.9 \pm 7.1$ \\
Trunk rotation $\left(^{\circ}\right)$ & $-7.1 \pm 8.4$ & $-7.0 \pm 8.5$ & $-10.8 \pm 9.3 * \mathrm{a}$ & $-11.1 \pm 7.3 * \mathrm{a}$ \\
Lateral trunk flexion & $1.9 \pm 5.2$ & $3.6 \pm 4.7$ & $9.8 \pm 5.4 * \mathrm{a}$ & $12.2 \pm 5.7$ *a \\
$\left(^{\circ}\right)$ & & & & \\
Step width $(\mathrm{m})$ & $-0.24 \pm 0.06$ & $-0.27 \pm 0.08$ & $-0.23 \pm 0.09$ & $-0.21 \pm 0.11$ \\
\hline
\end{tabular}

Table 1: Mean \pm SD values of the anticipatory postural strategies one step prior to the change of direction for the four cutting manoeuvre conditions (Ant, 850ms, 600ms, 500ms). Positive rotation values are orientated to the cutting direction, positive lateral flexion values are towards the left and negative step width values define a medial foot placement.

${ }^{* a}$ significant differences compared to Ant and 850ms cutting conditions $(\mathrm{p}<0.05)$ 
Table 2

\begin{tabular}{l|cccc}
\hline & Ant & $850 \mathrm{~ms}$ & $600 \mathrm{~ms}$ & $500 \mathrm{~ms}$ \\
\hline Head rotation $\left(^{\circ}\right)$ & $18.0 \pm 11.3$ & $17.6 \pm 13.1$ & $13.3 \pm 13.5 * \mathrm{a}$ & $13.5 \pm 11.5$ \\
Trunk rotation $\left(^{\circ}\right)$ & $-4.8 \pm 11.0$ & $-3.3 \pm 11.1$ & $-7.3 \pm 10.3 * \mathrm{~b}$ & $-8.8 \pm 9.9 * \mathrm{~b}$ \\
Lateral trunk flexion $\left(^{\circ}\right)$ & $5.3 \pm 6.1$ & $6.1 \pm 6.4$ & $10.4 \pm 6.4 * \mathrm{a}$ & $13.7 \pm 6.9 * \mathrm{a}, \mathrm{c}$ \\
Step width (m) & $0.36 \pm 0.03$ & $0.35 \pm 0.04$ & $0.36 \pm 0.03$ & $0.35 \pm 0.03$ \\
Foot progression angle $\left(^{\circ}\right)$ & $7.8 \pm 7.8$ & $9.2 \pm 7.9$ & $6.9 \pm 9.7$ & $6.3 \pm 9.8$ \\
\hline
\end{tabular}

Table 2: Mean \pm SD values of the postural strategies at the time of the peak knee abduction moment for the four cutting manoeuvre conditions (Ant, 850ms, 600ms, $500 \mathrm{~ms})$.

Positive rotation values are orientated to the cutting direction, positive lateral flexion values are towards the left and positive step width values define a lateral foot placement.

* expresses a significant difference:

a compared to Ant and 850ms cutting conditions

${ }^{\mathrm{b}}$ compared to the $850 \mathrm{~ms}$ cutting condition

${ }^{\mathrm{c}}$ compared to the $600 \mathrm{~ms}$ cutting condition 
Table 3

\begin{tabular}{l|cccc}
\hline & Ant & $850 \mathrm{~ms}$ & $600 \mathrm{~ms}$ & $500 \mathrm{~ms}$ \\
\hline Posterior force $\left(\mathrm{N} \cdot \mathrm{kg}^{-1}\right)$ & $5.42 \pm 2.51$ & $6.11 \pm 2.56$ & $7.38 \pm 2.25 * \mathrm{a}$ & $8.03 \pm 2.16 * \mathrm{a}, \mathrm{c}$ \\
Vertical force $\left(\mathrm{N} . \mathrm{kg}^{-1}\right)$ & $15.8 \pm 5.9$ & $17.1 \pm 7.0$ & $19.7 \pm 5.7 * \mathrm{a}$ & $20.8 \pm 5.9 * \mathrm{a}$ \\
Hip abduction moment $\left(\mathrm{Nm} . \mathrm{kg}^{-1}\right)$ & $2.01 \pm 0.78$ & $2.20 \pm 0.88$ & $2.55 \pm 0.74 * \mathrm{a}$ & $2.57 \pm 0.81 * \mathrm{a}$ \\
Knee abduction moment $\left(\mathrm{Nm} \cdot \mathrm{kg}^{-1}\right)$ & $1.00 \pm 0.48$ & $1.04 \pm 0.48$ & $1.21 \pm 0.47 * \mathrm{a}$ & $1.24 \pm 0.49 * \mathrm{a}$ \\
Contact Time (s) & $0.22 \pm 0.03$ & $0.22 \pm 0.03$ & $0.24 \pm 0.03 * \mathrm{a}$ & $0.25 \pm 0.04 * \mathrm{a}, \mathrm{c}$ \\
\hline
\end{tabular}

Table 3: Mean \pm SD values of the ground reaction forces (posterior and vertical), hip and knee abduction moments at the time of the peak knee abduction moment and of the contact time for the four cutting manoeuvre conditions (Ant, $850 \mathrm{~ms}, 600 \mathrm{~ms}$, $500 \mathrm{~ms})$.

* expresses a significant difference:

${ }^{a}$ compared to Ant and 850ms cutting conditions

${ }^{\mathrm{c}}$ compared to the $600 \mathrm{~ms}$ cutting condition 


\section{Figures captions}

Figure 1: Schematic representation of one subject performing the $45^{\circ}$ cutting manoeuvre to the right in response to the grey light stimulus. Figure A represents the end of the right foot contact, one step prior to the change of direction and Figure B the time of the peak knee abduction moment during the left foot contact.

Positive rotation values of the head, trunk and foot progression angle are orientated towards the cutting direction. Positive lateral trunk flexion values indicate a tilt of the trunk to the left. Positive step width values define a lateral foot placement with respect to the vertical projection of the hip joint centre.

Figure 2: Linear regression between peak knee abduction moment and lateral trunk flexion during the $45^{\circ}$ cutting manoeuvres. Values represent the difference from the Ant condition for the $850 \mathrm{~ms}$ (black diamonds), 600ms (grey circles) and 500ms (grey triangles) cutting conditions. 

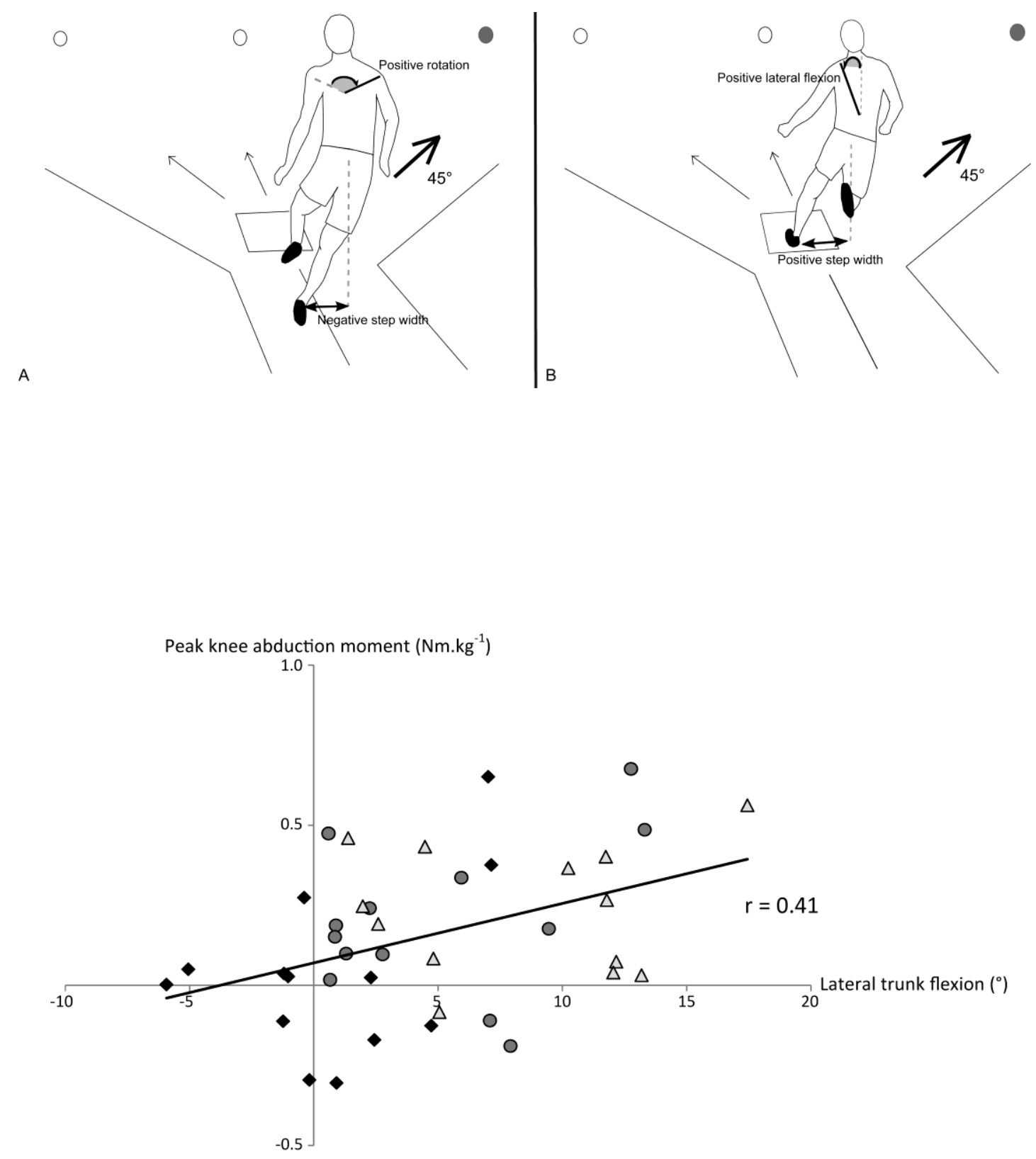